\title{
A Macrocyclic Calpain Inhibitor Slows the Development of Inherited Cortical Cataracts in a Sheep Model
}

\author{
James D. Morton, ${ }^{1}$ Hannab Y. Y. Lee, ${ }^{1}$ Josh D. McDermott, ${ }^{1}$ Lucinda J. G. Robertson, ${ }^{1}$ \\ Roy Bickerstaffe, ${ }^{1}$ Matthew A. Jones, ${ }^{2}$ James M. Coxon, ${ }^{2}$ and Andrew D. Abell ${ }^{*, 2}$
}

PurPose. We used sheep with an autosomal dominant gene for cortical cataract as an animal model to evaluate novel macrocyclic calpain inhibitors with potential for the medical treatment of human cataract.

Methods. The macrocyclic aldehyde, CAT811, identified previously as a calpain inhibitor that prevents calcium-induced opacification in cultured sheep lenses, was tested for its ability to protect cytoskeletal proteins from calpain proteolysis. CAT811 and its alcohol analogue, CAT505, were formulated separately into ointments, and each was applied twice daily to the right eye of sheep with early cataracts for five months. Progress of cataracts in the sheep was determined by ophthalmologic examination and comparison with a matched sample of sheep treated similarly with ointment that did not contain the active ingredient.

Results. The novel macrocyclic aldehyde, CAT811, was able to inhibit calpain proteolysis of lens cytoskeletal proteins at micromolar concentrations. When applied topically to the eyes of sheep, CAT811 was able to slow cataract development by $27 \%$ in the initial three months of treatment $(P<0.05)$. Its alcohol analogue, CAT505, was not able to slow cataractogenesis significantly.

Concuusions. The inherited sheep cataract provides a reproducible model of cortical cataract over a time scale of several months. The data reported here, using this model, demonstrated the potential of the macrocyclic calpain inhibitor, CAT811, to act as a therapeutic for treatment of cortical cataract. (Invest Ophthalmol Vis Sci. 2013;54:389-395) DOI: 10.1167/iovs.12-11088

ataracts are the leading cause of blindness in humans. ${ }^{1}$ They result from many causes, but the outcome in all cases is loss of lens transparency. Cataracts can be classified by their

From the ${ }^{1}$ Department of Wine, Food and Molecular Biosciences, Faculty of Agriculture and Life Sciences, Lincoln University, Canterbury, New Zealand; and the ${ }^{2}$ Department of Chemistry, University of Canterbury, Christchurch, New Zealand.

Supported by grants from the Foundation of Research Science and Technology of New Zealand (LINX0205) and Douglas Pharmaceuticals Limited.

Submitted for publication October 4, 2012; revised November 14 and 25, 2012; accepted November 26, 2012.

Disclosure: J.D. Morton, P; H.Y.Y. Lee, Douglas Pharmaceuticals Limited (F), P; J.D. McDermott, Douglas Pharmaceuticals Limited (F); L.J.G. Robertson, P; R. Bickerstaffe, P; M.A. Jones, P; J.M. Coxon, P; A.D. Abell, Calpain Therapeutics (I, C), P

Current affiliation: *School of Chemistry \& Physics, University of Adelaide, North Terrace, Adelaide, South Australia, Australia.

Corresponding author: James D. Morton, PO Box 84, Department of Wine, Food and Molecular Biosciences, Faculty of Agriculture and Sciences, Lincoln University, Canterbury 7647 , New Zealand; mortonj@lincoln.ac.nz.

Investigative Ophthalmology \& Visual Science, January 2013, Vol. 54, No. 1 Copyright 2013 The Association for Research in Vision and Ophthalmology, Inc. location in the lens, with the two most common types being cortical and nuclear. ${ }^{2}$

The lens nucleus consists of quiescent mature fiber cells that lack organelles and thereby rely on a nonoxidative metabolism. ${ }^{3}$ In contrast, the outer cortex is the site of intense activity where cuboidal epithelial cells differentiate into elongated fibrous cells. During this process, which has been likened to a partial apoptosis, ${ }^{4}$ the surface area-to-volume ratio of the cells increases dramatically and the organelles are lost. Associated with these cellular changes are dramatic alterations in protein synthesis and cytoskeleton rearrangement.

A rise in the intracellular concentration of $\mathrm{Ca}^{2+}$ results in enhanced degradation of proteins, which is significant in cortical, but not in nuclear cataracts. ${ }^{5}$ This has led to the hypothesis that inappropriate activation of the $\mathrm{Ca}^{2+}$-dependent cysteine proteases or calpains (EC 3.4.22.17) is important in cortical cataract. ${ }^{6}$ The overactivation of calpains has been implicated in a number of other human diseases, ${ }^{7,8}$ and there is extensive evidence that cytoskeletal and regulatory proteins are preferred calpain substrates. ${ }^{9}$ Exogenous calpain inhibitors have been used to investigate the role of calpains in human disorders, ${ }^{10}$ including cataract formation. ${ }^{11}$ While a number of calpain isoforms have been reported in the lens, calpain 2 is the dominant isoform in human ${ }^{12}$ and sheep ${ }^{13}$ lenses.

Exogenous calpain inhibitors could provide an attractive alternative to surgery for the treatment of cataract given the likely role of calpains in their development. A number of linear peptidometric inhibitors have shown some promise in lens culture and in vivo animal experiments. ${ }^{13,14}$ Our current study tests macrocyclic compounds that are constrained into a $\beta$ strand conformation ${ }^{15}$ that is known to favor binding to a protease, in this case calpain. ${ }^{16}$ Several of these compounds have been shown to be excellent in vitro calpain inhibitors ${ }^{17}$ with the best being CAT811, a compound containing a Cterminal aldehyde that had an IC50 of $30 \mathrm{nM}$ for calpain 2. The analogue with a less reactive alcohol in place of the aldehyde (Fig. 1, CAT505) also showed promise with an IC50 of $700 \mathrm{nM}$. Both compounds showed no inhibitory activity against papain, a-chymotrypsin, and pepsin when tested at concentrations up to $50 \mu \mathrm{M} .{ }^{17}$ However, both were potent inhibitors of cathepsin B with IC50s of 70 and $300 \mathrm{nM}$, respectively. Both inhibitors preferentially inhibited calpain 2 , the predominant calpain isoform in ovine lenses, ${ }^{13}$ over calpain $1 .^{17}$

Potential drugs for treating cataract already have been tested in a number of animal models and also with cultured lenses from several animal species. ${ }^{18-20}$ Rodent lenses have been the most commonly used, but these show significant biochemical and anatomic differences from human lenses. ${ }^{21} \mathrm{By}$ comparison, the sheep lens is similar anatomically to the human lens with its proteins showing greater homology to human lens proteins than those of rodents. ${ }^{22}$ Sheep lenses, therefore, are a particularly useful model. ${ }^{23}$ Previous work has shown that CAT811 is able to prevent calcium-induced cataract formation in lens culture, ${ }^{17}$ which confirmed that the 

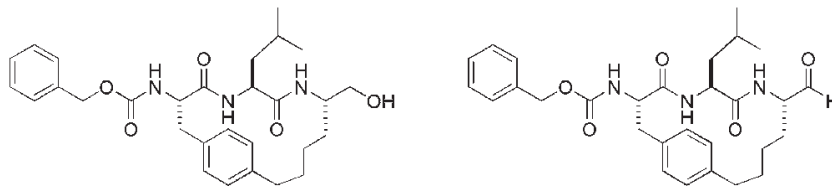

CAT505

CAT811
FiguRE 1. Macrocyclic calpain inhibitors CAT505 (molecular weight $[\mathrm{MWt}]=525.64)$ and CAT811 $(\mathrm{MWt}=523.6)$.

inhibitors can penetrate the lens. This is important, since earlier research has shown that the opacification involves inner fiber cells. This experiment also confirmed that the aldehyde inhibitor was effective in the high protein concentrations within the lens.

The sheep model used in our study involves a dominant mutation on chromosome 6 of sheep, which has been shown to lead to a reproducible inherited cortical cataract ${ }^{24}$ over a period of several months. Two earlier trials in this sheep model showed that acyclic calpain inhibitors were able to slow the progression of cataract for up to a month. ${ }^{13,23}$ We now report on the ability of the macrocyclic inhibitor CAT811 to prevent proteolysis of lens cytoskeletal proteins, and compare the ability of CAT811 and its alcohol analogue, CAT505, to slow cataract progression in this sheep model during an extended in vivo trial.

\section{Materials AND Methods}

\section{Synthesis and Formulation of Calpain Inhibitors}

CAT811 and CAT505 were synthesized as described previously ${ }^{17}$ and purified by HPLC. For the in vivo trial, they each were formulated into a crystal-free ointment ( $1 \%$ inhibitor molecule, $30 \%$ cetyl stearyl alcohol, $35 \%$ lanolin, and $34 \%$ paraffin wax). Ointment without inhibitor was used for the controls. These were partitioned into $1 \mathrm{~mL}$ syringes and stored at $4^{\circ} \mathrm{C}$ for up to 1 to 2 months before use.

\section{Animals}

All animal procedures were performed in accordance with Lincoln University Animal Ethics Protocol AEC\#154 as reviewed by the New Zealand Animal Ethics Committee, and in accordance with the ARVO Statement for the Use of Animals in Ophthalmic and Vision Research. Lenses for the cell-free system were from 9- to 11-month-old lambs collected from the local abattoir. The lambs used in the in vivo trials were from the Lincoln University cataract flock. ${ }^{13}$ At the start of the in vivo trial they were two months old with a mean weight of $21.5 \pm 4.6$ $\mathrm{kg}(N=63$ lambs $)$.

\section{Calpain Inhibitor Assay in a Cell-Free System}

A urea soluble fraction (USF) of the lens cortex was used to evaluate the effectiveness of the inhibitors in preventing cytoskeletal protein degradation. The outer cortex of six fresh sheep lenses was removed from the solidified nucleus tissue, yielding cortex tissue samples of an average wet weight of $495 \pm 0.01 \mathrm{mg}$. The separated cortex tissue then was homogenized in one volume of $20 \mathrm{mM}$ Tris-HCl buffer, $\mathrm{pH}$ 7.5, 1 mM EGTA, 1 mM EDTA, 2 mM DTT containing Complete, Mini protease inhibitor cocktail (Roche, Mannheim, Germany) prepared as per company instructions. This solution was centrifuged at $15,000 \mathrm{~g}$ for 1 hour. The pellet was washed three times by resuspension in $1 \mathrm{~mL}$ of homogenization buffer without protease inhibitors followed by recentrifugation. The washed pellet was resuspended in $100 \mu \mathrm{L}$ of 6 $\mathrm{M}$ urea and centrifuged at $15,000 \mathrm{~g}$ for 1 hour. The supernatant (USF) was collected and its protein content determined (BCA Protein Assay
Table 1. Progression of the Ovine Inherited Cataract

\begin{tabular}{ll}
\hline Stage & \multicolumn{1}{c}{ Description } \\
\hline 0 & Normal ovine lens \\
1 & Small opacity detected at either the anterior or posterior \\
& suture line \\
2 & Small opacities detected at both suture lines \\
3 & Opacities involved in $0 \%$ to $30 \%$ of the lens \\
4 & Opacities involved in $33 \%$ to $66 \%$ of the lens \\
5 & Total immature cataract - reflection from retina still visible \\
6 & Total mature cataract-no reflection from retina \\
7 & Hypermature cataract, displaying partial absorption of \\
& severely opaque lenses, leaving a fluid-filled lens remnant
\end{tabular}

Each number represents the stage of cataractogenesis (0-7) used to describe and score cataracts for the in vivo inhibitor treatments.

Kit; Pierce, Rockford, IL). The protein concentration of the USF then was adjusted to $10 \mathrm{mg} / \mathrm{mL}$ by the addition of $6 \mathrm{M}$ urea and the solution stored at $-20^{\circ} \mathrm{C}$.

Calpain 2 was purified from ovine lung. Briefly, $300 \mathrm{~g}$ of fresh ovine lung was homogenized and the calpains precipitated in 50\% ammonium sulfate (Sigma-Aldrich, St. Louis, MO). This was followed by a sequence of hydrophobic, ion-exchange, and dye ligand chromatography. The calpains were separated from their inhibitor calpastatin on a $300 \times 26 \mathrm{~mm}$ hydrophobic chromatography column (Phenyl Sephraose; GE Healthcare Bio-Sciences AB, Uppsala, Sweden). The column was loaded and washed in $0.5 \mathrm{M} \mathrm{NaCl}$ to elute calpastatin, and then the calpains were eluted in the absence of $\mathrm{NaCl}$. The pooled calpain was loaded onto a $350 \times 26 \mathrm{~mm}$ ion-exchange chromatography column (DEAE-Sepharose; GE Healthcare Bio-Sciences AB) and eluted with a $500 \mathrm{~mL} 0.1$ to $0.4 \mathrm{M} \mathrm{NaCl}$ linear gradient. This separated calpain 1 and 2 . The pooled calpain 2 fractions then were purified further on a $130 \times 16 \mathrm{~mm}$ dye ligand chromatography column (Reactive Red Agarose; Sigma-Aldrich) washed with $0.5 \mathrm{M} \mathrm{NaCl}$ and eluted without salt.

One mg of USF was incubated at $20^{\circ} \mathrm{C}$ for 1 hour with calpain 2 in the presence of $1.2 \mathrm{mM} \mathrm{Ca}^{2+}$ and inhibitor concentrations varying from 0 to $10 \mu \mathrm{M}$. The proteins were separated by electrophoresis on $4 \%$ to $12 \%$ Bis-Tris PAGE gels (NuPAGE; Invitrogen, Carlsbad, CA), stained with GelCode Blue (Pierce), and the optical density measured by Gel Doc EQ and Quantity One (Bio-Rad Laboratory, Hercules, CA). The results are the average of duplicate determinations.

The identity of the cytoskeletal proteins was confirmed by immunoblotting. After electrophoresis the proteins were transferred to a polyvinylidine difluoride (PVDF) membrane and incubated with the appropriate antibodies, namely polyclonal antispectrin (H-105) and monoclonal antivimentin (V9), sourced from Santa Cruz Biotechnology, Inc. (Santa Cruz, CA) and monoclonal antifilensin (Sigma-Aldrich). Immunoreactivity was visualized using the appropriate secondary antibodies and the alkaline phosphatase Conjugate Substrate Kit (BioRad Laboratories).

\section{Testing Macrocyclic Calpain Inhibitors In Vivo in a Sheep Model}

Overall Trial Design. Breeding of four sires with ovine heritable cataracts produced 208 lambs. Their eyes were assessed between the ages of one to two months to select 63 lambs that had right eyes with cataract scores of 1 to 3 (Table 1). This population was divided, by an independent statistician, into three comparable groups based on their body weight, sex, and cataract score. The groups consisted of a control group, a group for testing with CAT811, and a group for testing with CAT505.

The protocol specified the key data point to be that after three months of treatment. This was based on previous experience of the 


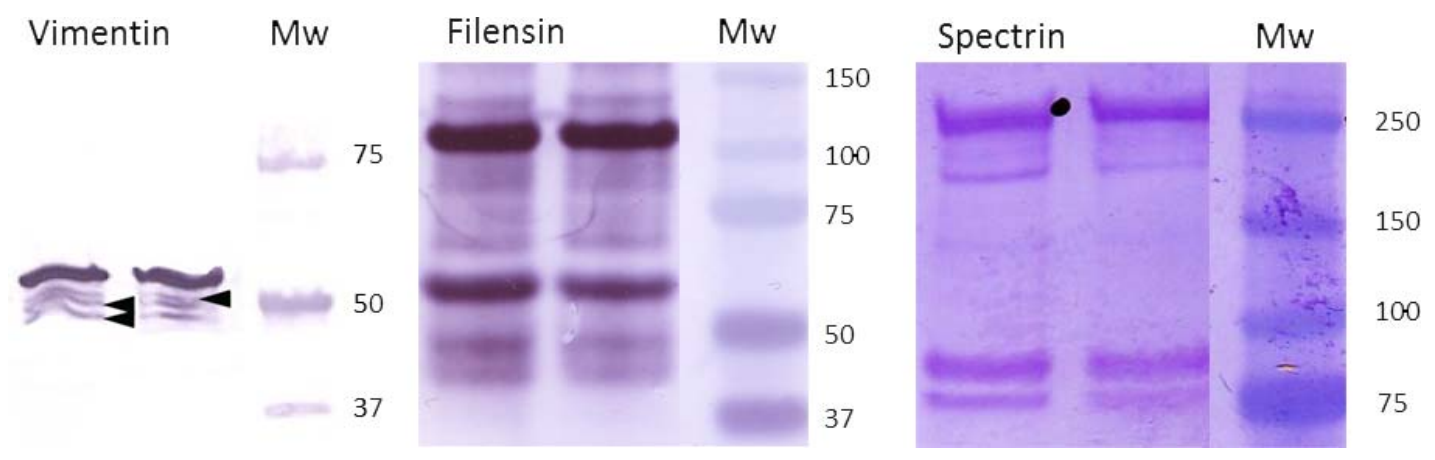

Figure 2. Immunoblots for vimentin, filensin, and spectrin in the urea soluble fraction $(10 \mu \mathrm{g} / \mathrm{lane})$ from the cortical region of normal sheep lenses. Fragments of vimentin are marked (arrowheads). Mw, molecular markers.

progression of sheep cataract to give the maximum chance of observing differences in rate of cataract formation with treatment.

All trial lambs were grazed together and yarded twice daily for treatment of the right eye only with 17 to $23 \mathrm{mg}$ of ointment containing 170 to $230 \mu \mathrm{g}$ of either CAT811 or CAT505. All lambs in the treatment trials were yarded at monthly intervals to assess cataract scores in the treated and untreated eyes by an independent veterinary ophthalmologist who was unaware of which eyes had been treated. The assessment was done using a slit-lamp microscope (Kowa SL-T; Kowa Co. Ltd., Tokyo, Japan) in a darkened room as described previously. ${ }^{13}$ The progress of cataract development was scored using an established 8-point scale ${ }^{23}$ as described in Table 1.

Animal Health. Condition scores of the sheep were measured at the start and the end of the 5-month trial. Three lambs from each treatment group had $5 \mathrm{~mL}$ blood samples taken by venipuncture at the start and end of the trial. These were centrifuged ( $1200 \mathrm{~g}$ for 15 minutes) and the serum stored at $-80^{\circ} \mathrm{C}$ before being sent to a veterinary pathology laboratory for biochemical analysis (Gribbles Veterinary, Christchurch, NZ). Live body weights of the sheep were monitored and recorded throughout the trials.

\section{Statistical Analysis}

Significant decreases in loss of band density of cytoskeletal proteins during the cell-free assay were determined by independent $t$-tests comparing the mean band density in the presence and absence of inhibitor (Minitab, version 15; Minitab Inc., State College, PA). Independent $t$-tests were used in the in vivo trial to determine whether the calpain inhibitors slowed cataract progression in the treated animals by comparing the mean changes between each treatment with the control group. A 2 -tailed $P$ value $<0.05$ was taken to indicate statistical significance.

An earlier trial, where CAT811 was applied as an ointment to one eye of lambs, revealed no observable difference between the treated and untreated eye of each individual lamb (Morton JD, Lee HYY, Robertson LJG, unpublished data, 2006). However, the rate of cataract progress was slower in those lambs treated with CAT811 relative to those treated with the acyclic inhibitor, CAT0059, ${ }^{23}$ indicating a pathway for crossover between the eyes. As there was no evidence of a difference between the treated right eye and the left eye with either CAT505 or CAT811 in the current trial, the cataract scores of both eyes were combined for the analyses.

\section{Results}

\section{CAT811 Inhibits Proteolysis of Cytoskeletal Proteins}

The ability of CAT811 to inhibit the degradation of key cytoskeletal proteins also was assessed in vitro. The presence of spectrin, filensin, and vimentin in the USF of sheep lens was confirmed by immunoblotting (Fig. 2). When this fraction was incubated with purified ovine calpain 2 and $1.2 \mathrm{mM} \mathrm{Ca}^{2+}$, marked proteolysis of all three proteins was observed (Fig. 3). This did not occur when a similar fraction was incubated with

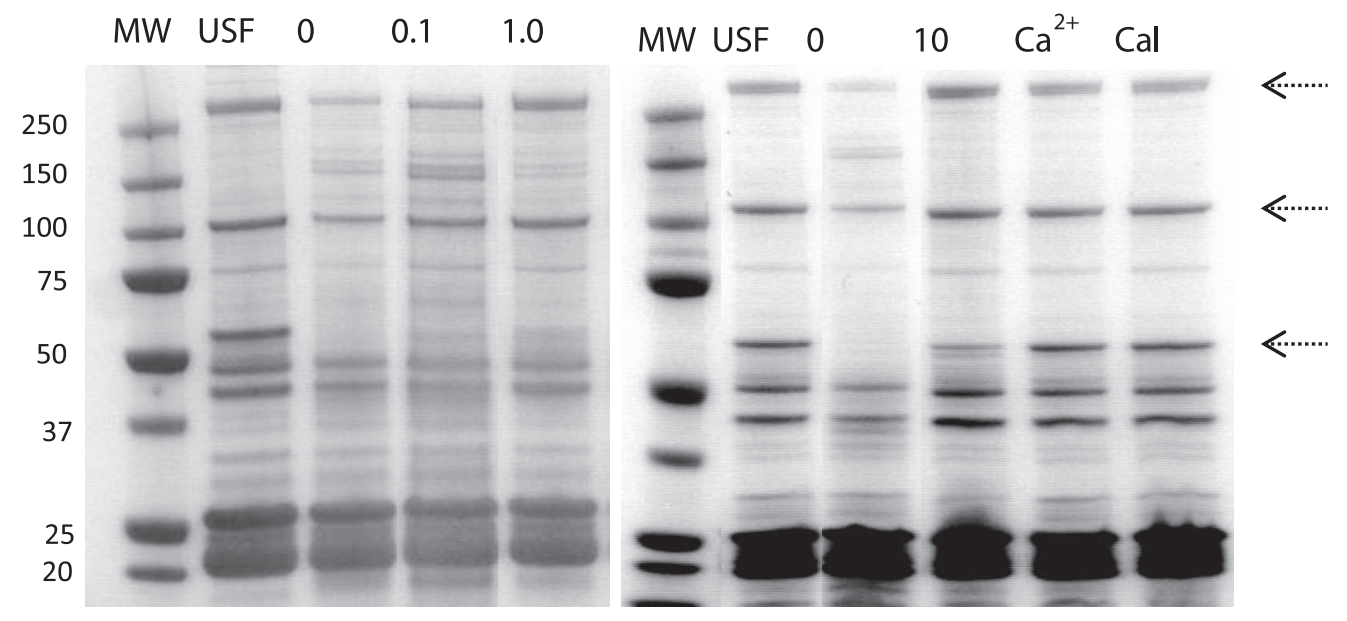

FIGURE 3. SDS PAGE (4\%-12\%) protein profiles with the urea soluble fraction of sheep lens illustrating the efficacy of CAT811 in preventing calpain proteolysis of lens cytoskeletal proteins. The arrows indicate intact spectrin $(280 \mathrm{kDa})$, filensin $(115 \mathrm{kDa})$, and vimentin $(57 \mathrm{kDa})$. The USF of sheep lens was incubated with purified sheep calpain 2 and $1.2 \mathrm{mM} \mathrm{Ca}^{2+}$ in the presence of $0,0.1,1.0$, and $10 \mu \mathrm{M}$ of CAT811. Ca ${ }^{2+}$, USF incubated with $1.2 \mathrm{mM} \mathrm{Ca}{ }^{2+}$; Cal, USF with purified ovine calpain 2. 
TaBLe 2. Efficacy of CAT811 in Preventing Calpain Proteolysis of Lens Cytoskeletal Proteins

\begin{tabular}{|c|c|c|c|c|c|c|}
\hline \multirow[b]{2}{*}{ Proteins } & \multirow[b]{2}{*}{$N$} & \multirow[b]{2}{*}{ USF } & \multicolumn{4}{|c|}{ Concentration of CAT811 } \\
\hline & & & $\mathbf{0} \mu \mathbf{M}$ & $0.1 \mu \mathrm{M}$ & $1.0 \mu \mathrm{M}$ & $10 \mu \mathrm{M}$ \\
\hline Vimentin & 2 & $1.00 \pm 0.01$ & $0.54 \pm 0.04$ & ND & $0.69 \pm 0.07$ & $1.00 \pm 0.08^{*}$ \\
\hline Spectrin & 4 & $1.00 \pm 0.01$ & $0.65 \pm 0.04$ & $0.76 \pm 0.15$ & $0.94 \pm 0.04^{*}$ & $1.23 \pm 0.01^{*}$ \\
\hline Filensin & 4 & $1.00 \pm 0.03$ & $0.82 \pm 0.08$ & $0.87 \pm 0.02$ & $0.91 \pm 0.05^{*}$ & $1.07 \pm 0.01 *$ \\
\hline
\end{tabular}

The mean band optical density ( \pm SEM) spectrin, filensin, and vimentin following proteolysis in the presence of different concentrations of CAT811 are expressed as a proportion of the density in USF. No intact vimentin was visible following application of $0.1 \mu \mathrm{M} 811$ (ND).

${ }^{*}$ Indicates that these inhibitor treatments resulted in a significant decrease in proteolysis for that protein $(P<0.05$, two-sample $t$-test $)$.

either $\mathrm{Ca}^{2+}$ or calpain alone. The macrocyclic calpain inhibitor, CAT811, was shown to protect significantly intact spectrin and filensin from $\mathrm{Ca}^{2+}$-induced calpain degradation at a concentration of $0.1 \mu \mathrm{M}$ (Table 2). Vimentin was the most sensitive of the three cytoskeletal proteins to proteolysis by calpain 2 and required $10 \mu \mathrm{M}$ CAT811 to protect it from proteolysis.

\section{Evaluation of CAT811 and CAT505 Efficacy with Ovine Inherited Cataract}

The two compounds were tested for their ability to slow cataract progression when applied twice daily as an ointment to the sheep. The lambs with cataracts were divided into three groups to receive separately placebo, CAT811, or CAT505 (Table 3). The cataract scoring system was used to evaluate the rate of cataract development over the treatment periods (Table 1). At the start of the trial almost $88 \%$ of the lenses were scored at either 1 or 2 .

The lenses of the lambs were scored at approximately monthly intervals over a period of five months. The first observation of note was that there was no difference in mean cataract score between treated and untreated eyes within each group, as we had noted previously. As discussed earlier, this provides evidence that the compounds were affecting both eyes. Therefore, all results reported herein are mean cataract scores for both eyes of each sheep within each group.

During the lens analysis, the veterinary ophthalmologist determined that one animal (228) in the placebo group had been misdiagnosed as its initial opacity had actually cleared with time. Thus, the data from this animal were removed from the trial. Two other lambs, one in the placebo group (130) and one in the CAT811 treatment group (209), showed no change in their opacities over the five months and also were removed from the analysis.

The predetermined key point for analysis of efficacy was 3 months. During this time the mean lens opacity in the control group increased from 1.82 to 4.66 , a change in score of 2.84 . Over the same period the score of the lambs treated with

TABLE 3. Mean Cataract Scores of Both Eyes, Live Weight of Lambs, and Condition Scores of All Experimental Sheep ( \pm SD) during the In Vivo Drug Application

\begin{tabular}{lcccc}
\hline & & \multicolumn{3}{c}{ Treatment Group } \\
\cline { 2 - 5 } & Mo & Placebo & CAT811 & CAT505 \\
\hline \multirow{2}{*}{$N$ of sheep } & & 19 & 20 & 21 \\
Mean cataract scores & 0 & $1.82 \pm 0.89$ & $1.80 \pm 0.79$ & $1.71 \pm 0.72$ \\
& 3 & $4.66 \pm 1.51$ & $3.88 \pm 1.53$ & $3.98 \pm 1.46$ \\
Live body weight, kg & 5 & $5.58 \pm 1.24$ & $5.00 \pm 1.52$ & $5.21 \pm 1.08$ \\
Condition scores & 0 & $21.0 \pm 4.1$ & $21.6 \pm 5.6$ & $22.1 \pm 4.4$ \\
& 3 & $32.7 \pm 5.0$ & $31.8 \pm 5.8$ & $33.8 \pm 4.8$ \\
& 0 & $2.1 \pm 0.4$ & $2.2 \pm 0.5$ & $2.1 \pm 0.4$ \\
& 5 & $2.0 \pm 0.4$ & $2.1 \pm 0.4$ & $2.1 \pm 0.3$ \\
\hline
\end{tabular}

CAT811 increased by 2.08 , which represents a $27 \%$ slowing in the development of cataracts $(P<0.05$, Fig. 4$)$. The opacity of lenses in lambs treated with CAT505 increased by 2.26. However, there was significant variation in progression within each group and in this case the difference from the placebo was not significant $(P=0.12)$.

The lambs were between 7 and 8 months of age by the end of the trial, and $75 \%$ had mature cataracts (stages 5-7, Fig. 5). This rate of progression of cataract was within the range reported in earlier trials involving similar animals from the Lincoln cataract flock. ${ }^{13,23}$

The lambs were treated for a further two months, with no further significant differences between drug-treated and placebo groups apparent after three months. This was considered to be a result of the plateau in the control group, since a high proportion of these lambs already had mature cataract.

All three groups showed similar growth with all animals maintaining their condition through the course of the trial (Table 3). As such, the prolonged daily treatment, with either CAT811 or CAT505, did not result in any apparent harm to the lambs.

Analysis of serum enzymes revealed no evidence of liver damage with either the CAT811- or CAT505-treated sheep (Table 4). Although the values of aspartate transaminase (AST) increased with age, all were within the normal range and while gamma glutamyl transferase (GGT) was slightly above the normal range, the highest values were found in the placebo animals.

There also was no evidence of either kidney damage or increased protein turnover with any of the treatments. Serum levels of creatinine were low in all samples and urea was within the normal range. Both values increased with increasing

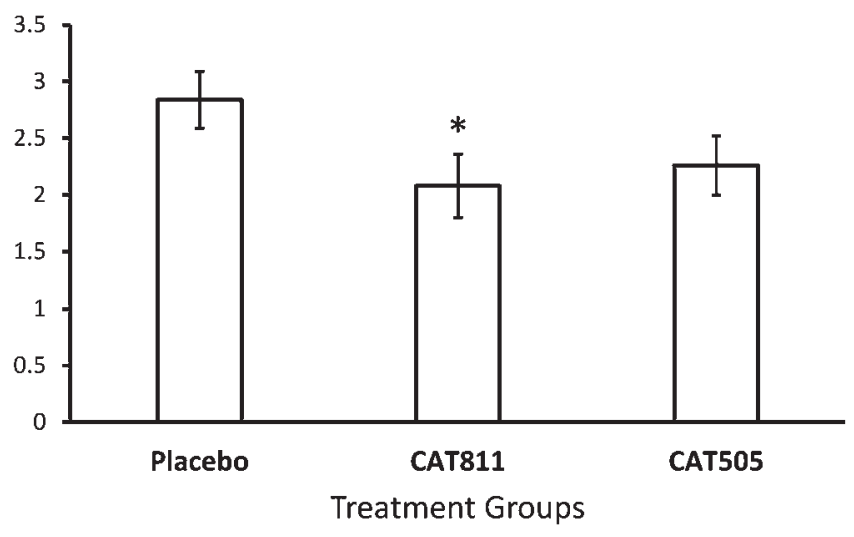

Figure 4. Treatment of cataract ovine lenses with CAT811 and CAT505. The graph shows the difference in mean cataract scores $( \pm$ SEM), as measured by the independent veterinary ophthalmologist, between the start of the trial and after three months (96 days). Two tail $t$-test, ${ }^{*} P<0.05$. 


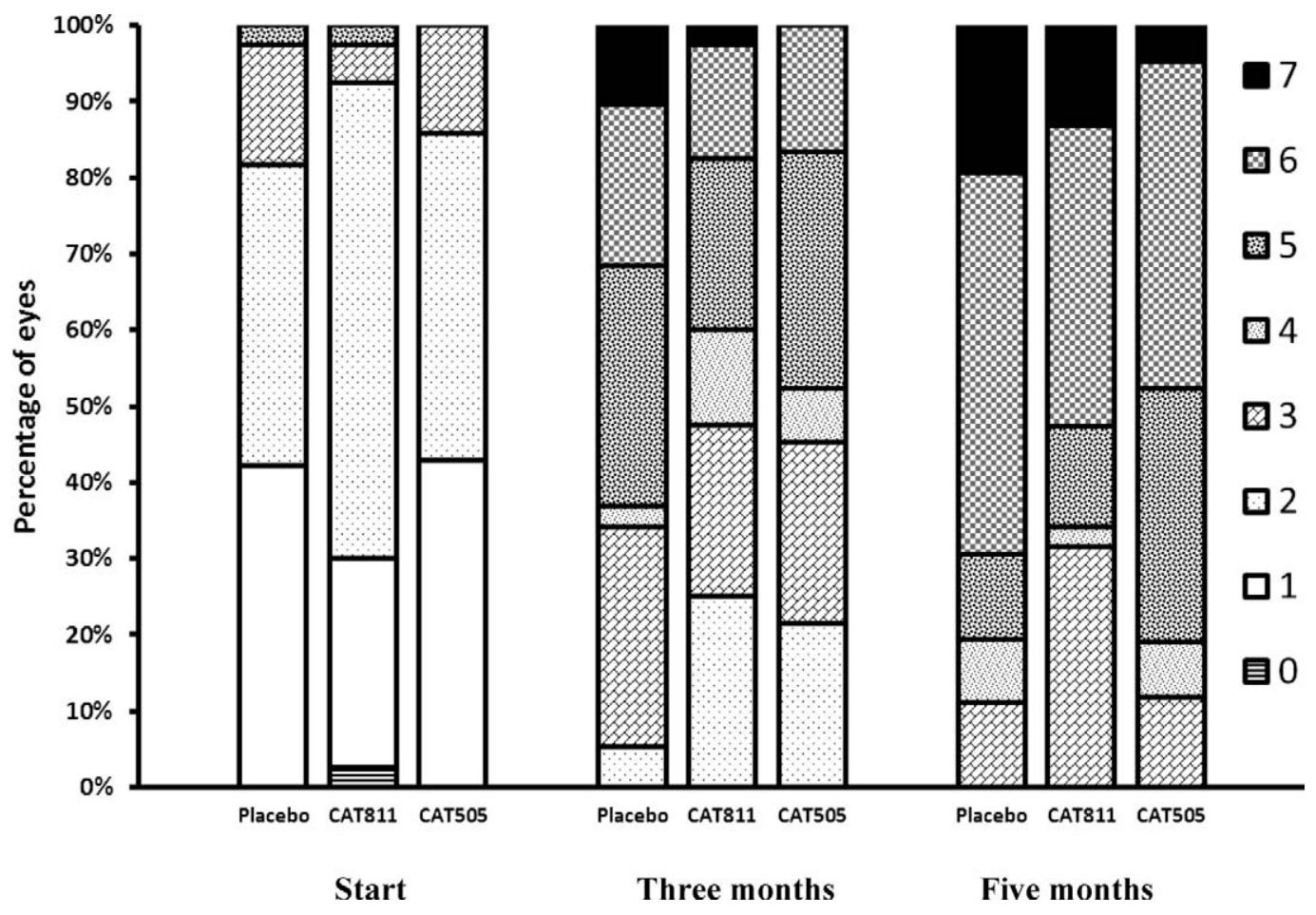

Figure 5. The cataract scores are shown for each group at the start of the trial, and after three months ( 96 days) and five months of treatment (153 days)

age of the animals, but there was no difference between the treatment groups.

\section{Discussion}

Our report compares the effectiveness of two macrocyclic calpain inhibitors, CAT811 and CAT505. The conformational constraint introduced by the macrocycle of this new generation of inhibitors appears to offer improved potency and selectivity compared to acyclic inhibitors. These macrocyclic structures also have improved biostability with improved resistance to other proteases. CAT811, with an aldehyde warhead, was the most effective inhibitor in vitro and it showed selectivity for calpain 2, the dominant calpain isoform in human and sheep lenses. CAT505 was less effective in vitro, but it may be useful in vivo and in other indications as the alcohol is less reactive than the aldehyde of CAT811.
Cytoskeletal proteins are important particularly in lenses as the transition from epithelial cells to elongated fiber cells relies on extensive synthesis and rearrangement of the cytoskeleton. These proteins also are important physiologic substrates for calpain. Several investigators have proposed that calpain's involvement in human cataract may be a result of its disruption of the cytoskeleton. ${ }^{13,20,25}$ In a proteomic analysis of changes in crystallins and other lens proteins during formation of the ovine hereditary cataract, cytoskeletal proteins were lost from the water-insoluble fraction. ${ }^{26}$ Other research ${ }^{23}$ has shown that ovine lens spectrin, the anchor for the actin network, and the two intermediate filament proteins, filension and vimentin, are proteolyzed by ovine calpain 2 . In our study, we have shown that CAT811 is able to inhibit this proteolysis. The high sensitivity of vimentin also was noted in earlier research where $1.0 \mu \mathrm{M}$ of the acyclic inhibitor SJA6017 was protective. ${ }^{23}$

The inhibitors were administered as ointments to lambs with inherited cataracts over a period of five months. The gene causing cataract is inherited in an autosomal dominant manner

TABLE 4. Biochemical Analysis of Serum Markers of Toxicity (Means \pm SEM)

\begin{tabular}{|c|c|c|c|c|}
\hline Treatment & AST, IU/L & GGT, IU/L & Creatinine, $\mu \mathrm{mol} / \mathbf{L}$ & Urea, mmol/L \\
\hline Normal range & 44 to 123 & 0 to 55 & 105 to 170 & 3.9 to 11.3 \\
\hline \multicolumn{5}{|l|}{ Start of trial } \\
\hline Placebo & $70.3 \pm 12$ & $75 \pm 8.5$ & $58 \pm 8.9$ & $5.53 \pm 0.84$ \\
\hline CAT811 & $77 \pm 13$ & $54.7 \pm 5.8$ & $58.33 \pm 2.8$ & $5.2 \pm 0.12$ \\
\hline CAT505 & $89.33 \pm 5.2$ & $63.67 \pm 0.88$ & $52.67 \pm 4.1$ & $5.17 \pm 0.64$ \\
\hline \multicolumn{5}{|l|}{ End of trial } \\
\hline Placebo & $100 \pm 8.6$ & $75.3 \pm 12$ & $76.67 \pm 4.3$ & $10.17 \pm 0.97$ \\
\hline CAT811 & $107.7 \pm 12$ & $63.7 \pm 4.7$ & $75 \pm 5.1$ & $9.63 \pm 0.97$ \\
\hline CAT505 & $122.7 \pm 10$ & $38.7 \pm 7.6$ & $70.67 \pm 5.6$ & $10.1 \pm 1.5$ \\
\hline
\end{tabular}

Serum samples were taken from three animals from each treatment group at the beginning and end of the five-month trial. They were analyzed for liver function with AST and GGT, and for kidney and muscle damage with creatinine and urea. 
with limited penetrance. ${ }^{24}$ This meant that when a ram carrying the mutation is mated with normal-eyed ewes approximately $40 \%$ of the offspring will have cataract. Selection of animals for this trial was completed by a veterinary ophthalmologist when the lambs were less than 2 months old and most of the lenses were scored with small opacities. Although this normally is predictive of inherited cataract, one of the 64 lambs identified was later diagnosed not to have cataract and another two did not progress from the initial opacity over the five months of the trial. In comparison, all the other lenses progressed at least two grades with three quarters having mature cataracts. On this basis these three animals were removed from the trial.

Although the ointment was administered only to the right eye of the lambs, the analysis compared all lenses from treated sheep to those of the controls. This was done because there was no observable difference in the rate of progression between treated and untreated eyes within a treatment group. The assumption was made that the compounds were able to transfer to the other eye, with such a transfer having been reported in humans using topical agents for glaucoma ${ }^{27}$ and also has been found in this ovine model with the acyclic calpain inhibitor, SJA6017. ${ }^{13}$ Research to confirm this process using a tritiated analogue of CAT505 will be published separately.

The inherited propensity for cataract in sheep described here provides a natural large mammal model of human cataract. Normal progression of cataract leads to mature cataract in lambs at 6 to 8 months of age. This then provides a suitable accelerated model for the evaluation of potential topically applied treatment of cataract in humans. Earlier in vivo trials with the acyclic calpain inhibitors SJA6017 13 and CAT0059 $9^{23}$ demonstrated their ability initially to slow progression for up to a month. In this research, CAT811 was shown to slow the progression of cortical cataracts in these lambs by $27 \%$ over three months relative to untreated animals. This is a significant result in the context of the relatively rapid progression of cataracts in this model as compared to humans. Cortical cataracts are the most common type of human cataract ${ }^{2}$ and usually take many years to develop. A treatment that slows this progression by a similar amount could greatly delay or even remove the need and urgency for surgery. It has been estimated that delaying surgery for 10 years would halve the requirement for cataract surgery. ${ }^{28}$

The potential of CAT811 to prevent or slow cataract development in humans is dependent on the importance of calpain in the human lens. Calpain 2 has been shown to be the dominant isoform in human lens ${ }^{12}$ and calcium-induced proteolysis was confirmed in human lens culture model of cataract. $^{6}$ It has been proposed that there was only limited activity of the calpains in primate lenses based largely on the lack of crystallin proteolysis. ${ }^{29}$ However, a more recent study from the same group ${ }^{25}$ has confirmed earlier results that the role of calpain may be targeted to key cytoskeletal proteins in the epithelial cell layer. This suggests that calpain inhibitors may be useful in treating human cataracts. CAT811 also is a potent inhibitor of the lysosomal protease, cathepsin $\mathrm{B},{ }^{17}$ but is more likely to be acting as a calpain inhibitor because mature lens fiber cells lack lysosomes and within the epithelium the target proteins are in the cytoplasm.

In conclusion, the topical application of CAT811 to an eye is a promising approach for slowing the development of cataracts. This research has shown it is effective and safe in a prolonged trial in a large animal model. It now must be tested in human lenses and also consideration given to a more effective delivery system.

\section{Acknowledgments}

Steve Heap (veterinary ophthalmologist, McMaster \& Heap Veterinary Practice, Christchurch, NZ) determined the stage of cataracts in the sheep eyes and Chris Frampton (consultant statistician, Statistecol) provided statistical design and analysis.

\section{References}

1. Resnikoff S, Pascolini D, Etya'ale D, et al. Global data on visual impairment in the year 2002. Bull World Health Org. 2004;82: 844-851.

2. Sasaki K, Sasaki H, Jonasson F, Kojima M, Cheng, HM. Racial differences of lens transparency properties with aging and prevalence of age-related cataract applying a WHO classification system. Ophthalmic Res. 2004;36:332-340.

3. Augusteyn RC. On the growth and internal structure of the human lens. Exp Eye Res. 2010;90:643-654.

4. Bassnett S. On the mechanism of organelle degradation in the vertebrate lens. Exp Eye Res. 2009;88:133-139.

5. Duncan G, Bushell AR. Ion analysis of human cataractous lenses. Exp Eye Res. 1975;20:223-230.

6. Sanderson J, Marcantonio JM, Duncan G. A human lens model of cortical cataract: $\mathrm{Ca}^{2+}$-induced protein loss, vimentin cleavage and opacification. Invest Ophthalmol Vis Sci. 2000; 41:2255-2261.

7. Niapour M, Farr C, Minden M, Berger SA. Elevated calpain activity in acute myelogenous leukemia correlates with decreased calpastatin expression. Blood Cancer J. 2012;2:e51.

8. Yamada KH, Kozlowski DA, Seidl SE, et al. Targeted gene inactivation of calpain-1 suppresses cortical degeneration due to traumatic brain injury and neuronal apoptosis induced by oxidative stress. J Biol Chem. 2012;287:13182-13193.

9. Tompa P, Buzder-Lantos P, Tantos A, et al. On the sequential determinants of calpain cleavage. J Biol Chem. 2004;279: 20775-20785.

10. Pietsch M, Chua KCH, Abell AD. Calpains: attractive targets for the development of synthetic inhibitors. Curr Top Med Chem. 2010;10:270-293.

11. Azuma M, David LL, Shearer TR. Cysteine protease inhibitor E64 reduces rate of formation of selenite cataract in the whole animal. Curr Eye Res. 1991;10:657-666.

12. David LD, Varnum MD, Lampi KJ, Shearer TR. Calpain II in human lens. Invest Ophthalmol Vis Sci. 1989;30:269-275.

13. Robertson LJG, Morton JD, Yamaguchi M, Bickerstaffe R, Shearer TR, Azuma M. Calpain may contribute to hereditary cataract formation in sheep. Invest Ophthalmol Vis Sci. 2005; 46:4634-4640.

14. Lee HYY, Morton JD, Sanderson J, Bickerstaffe R, Robertson LJG. The involvement of calpains in opacification induced by $\mathrm{Ca}^{2+}$-overload in ovine lens culture. Vet Ophthalmol. 2008;11: 347-355.

15. Stuart BG, Coxon JM, Morton JD, et al. Molecular modeling: a search for a calpain inhibitor as a new treatment for cataractogenesis. J Med Chem. 2011;54:7503-7522.

16. Tyndall JDA, Nall T, Fairlie DP. Proteases universally recognize beta strands in their active sites. Chem Rev. 2005;105:973999.

17. Abell AD, Coxon JM, Jones MA, et al. Molecular modeling, synthesis and biological evaluation of macrocyclic calpain inhibitors. Angew Chem Int Ed Eng. 2009;48:1455-1458.

18. Azuma M, David LL, Shearer TR. Superior prevention of calcium ionophore cataract by E64d. Biochim Biophys Acta. 1992;1180:215-220.

19. Fukiage C, Azuma M, Nakamura Y, Tamada Y, Nakamura M, Shearer TR. SJA6017, a newly synthesized peptide aldehyde 
inhibitor of calpain: amelioration of cataract in cultured rat lenses. Biochim Biophys Acta. 1997;1361:304-312.

20. Sanderson J, Marcantonio JM, Duncan G. Calcium ionophore induced proteolysis and cataract: inhibition by cell permeable calpain antagonists. Biochem Biophys Res Comm. 1996;218: 893-901.

21. Augusteyn RC, Stevens A. Macromolecular structure of the eye lens. Prog Polym Sci. 1998;23:357-413.

22. Jones MA, Morton JD, Coxon JM, et al. Synthesis, biological evaluation and molecular modelling of N-heterocyclic dipeptide aldehydes as selective calpain inhibitors. Bioorg Med Chem. 2008;16:6911-6923.

23. Lee HYY, Morton JD, Robertson LJG, et al. Evaluation of a novel calpain inhibitor as a treatment for cataract. Clin Experiment Ophthalmol. 2008;36:852-860.

24. Wilson GRS, Morton JD, Palmer DN, et al. The locus for an inherited cataract in sheep maps to ovine chromosome 6. Mol Vis. 2012;18:1384-1394.
25. Nakajima T, Shearer TR, Azuma M. Involvement of calpain 2 in ionomycin-induced cell death in cultured mouse lens epithelial cells. Curr Eye Res. 2011;36:930-936.

26. Robertson LJG, David LL, Riviere MA, Wilmarth PA, Muir MS, Morton JD. Susceptibility of ovine lens $\alpha$ - and $\beta$ crystallins to proteolytic cleavage during formation of hereditary cataract. Invest Ophthalmol Vis Sci. 2008;49: 1016-1022.

27. Piltz J, Gross R, Shin DH, et al. Contralateral effect of topical beta-adrenergic antagonists in initial one-eyed trials in the ocular hypertension treatment study. Am J Ophthalmol. 2000; 130:441-453.

28. Taylor HR, Keeffe JE. World blindness: a 21st century perspective. Br J Ophthalmol. 2001;85:261-266.

29. Nakajima E, Walkup $\mathrm{RD}$, Ma $\mathrm{H}$, et al. Low activity by the calpain system in primate lenses causes resistance to calciuminduced proteolysis. Exp Eye Res. 2006;83:593-601. 